\title{
Poly(vinyl alcohol) Based Polymer Gel Electrolytes: Investigation on Their Conductivity and Characterization
}

\author{
S. ÇAVUş* AND E. Durgun \\ Department of Chemical Engineering, Faculty of Engineering, Istanbul University, Avcilar, 34320, Istanbul, Turkey
}

\begin{abstract}
Polymer gel electrolytes were prepared using poly(vinyl alcohol) (PVA) as polymer matrix. 1-methyl-2pyrrolidone (NMP) and $\gamma$-butyrolactone (GBL) were preferred as the organic solvents. The alkali metal iodide salt $(\mathrm{KI})$ and iodine $\left(\mathrm{I}_{2}\right)$ were used as the redox couple. Liquid electrolytes with different concentrations of KI were prepared by dissolving iodide salt/iodine in the binary NMP:GBL (volume ratio 7:3) solvent mixture. PVA was added into the liquid electrolytes and then the resulting mixture was stirred at $110^{\circ} \mathrm{C}$ for $1 \mathrm{~h}$. Gel form was obtained at room temperature. The highest ionic conductivity at room temperature is $8.41 \mathrm{mS} / \mathrm{cm}$. The temperature dependence of ionic conductivity with respect to the all concentration of KI shows the Arrhenius behaviour. Characterizations of polymer gel electrolytes were performed using the Fourier transform infrared, thermal gravimetric analysis, and differential scanning calorimetry techniques.
\end{abstract}

DOI: 10.12693/APhysPolA.129.621

PACS/topics: $82.45 . \mathrm{Wx}$

\section{Introduction}

Development of polymer gel electrolytes has gained much importance during the last decades. Ionic conductivity values of polymer gel electrolytes are very high in comparison with that of solid polymer electrolytes [1]. Liquid electrolytes have disadvantages owing to volatilization of solvent and leakage problems, and this situation creates drawbacks for long term applications [2]. The problems that are caused by liquid electrolytes have been reduced with the use of gel electrolytes. Dyesensitized solar cells (DSSCs) display great performance in terms of the high light-electricity conversion, easy fabrication and low cost. In the DSSCs, polymer electrolytes and liquid electrolytes can be used [3]. However, using of polymer gel electrolytes contributes positively to long-term stability and they provide an improvement with respect to the contacting and filling properties for DSSC [4]. The liquid electrolytes contain organic solvents with high boiling points (i.e. $\gamma$-butyrolactone, ethylene carbonate, propylene carbonate) and inorganic salts like lithium iodide, sodium iodide and potassium iodide. A gel electrolyte is prepared by absorbing liquid electrolytes [2].

Poly(vinyl alcohol) is one of the biodegradable synthetic polymer that have good optical features, low cost, non-toxicity, hydrophilicity and high dielectric constant [5]. In addition to combined high mechanical strength and temperature resistance [5], the $\mathrm{O}-\mathrm{H}$ groups in PVA, a source of H-bonding, are capable of constructing polymer complexes [6]. The dissolution of the salt is easy due to presence of polar groups $(-\mathrm{OH})$ and high chain flexibility [5].

\footnotetext{
*corresponding author; e-mail: selva@istanbul.edu.tr
}

In the present study, a polymer gel electrolyte was prepared using PVA as polymer matrix, NMP, and GBL as the solvents and $\mathrm{KI}+\mathrm{I}_{2}$ as the redox couple. The ion transport mechanism for the gel electrolyte system based on PVA is determined, and it was found that the Arrhenius equation is suitable with respect to the temperature dependence of the ionic conductivity.

\section{Experimental \\ 2.1. Materials}

Poly(vinyl alcohol) with a average molecular weight of 72,000 (PVA72000) was supplied by Merck Schuchardt OHG (Hohenbrunn/Germany) and it was used as received. $\gamma$-butyrolactone $(\geq 99 \%)$ and 1-methyl-2-pyrrolidone (99\%) were from Aldrich (Steinheim/Germany) and Sigma-Aldrich (Steinheim/Germany), respectively. Potassium iodide (KI) and iodine $\left(\mathrm{I}_{2}\right)$ were obtained from Merck KGaA (Darmstadt/Germany) and Riedel-de Haën Seelze Germany, respectively.

\subsection{Preparation of polymer gel electrolytes}

Liquid electrolytes were obtained by completely dissolving $\mathrm{KI}+\mathrm{I}_{2}$ in the binary solvent mixture of NMP:GBL $(7: 3, \mathrm{v} / \mathrm{v})$ keeping the iodide salt/iodine mol ratio constant at 10:1. Concentration of KI is varied from 0.2 to $1 \mathrm{~mol} / \mathrm{L}$ in the liquid electrolytes. PVA (3 wt\%) was added into the liquid electrolyte and this mixture was settled into preheated oil bath $\left(110^{\circ} \mathrm{C}\right)$ and stirred for $1 \mathrm{~h}$. After heating, sample was kept at room temperature to cool down naturally and a polymer gel electrolyte was obtained in the form of gel. The view of the polymer gel electrolyte is shown in Fig. 1. It is clear that polymer gel electrolyte has a stable form. 


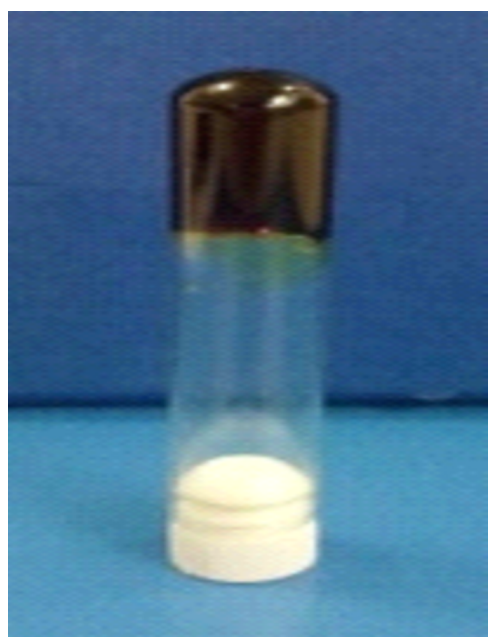

Fig. 1. The view of a gel electrolyte based on PVA.

\subsection{Characterization studies}

The ionic conductivity of the polymer gel electrolytes was measured using a conductivity meter (Jenco 3173). The instrument was calibrated with freshly prepared 0.1 $\mathrm{KCl}$ solution before each measurement [3]. The Fourier transform infrared (FTIR) analysis was performed by NICOLET 380 FT-IR (Thermo ELECTRON CORPORATION) in the range of $400-4000 \mathrm{~cm}^{-1}$ using a mixture containing sample and $\mathrm{KBr}$ (FTIR grade). Differential scanning calorimetry (DSC, Shimadzu DSC-60) was used for thermal characterization of the polymer gel electrolytes. Analyses were carried out under a nitrogen atmosphere $(20 \mathrm{~mL} / \mathrm{min})$ at a heating rate of $10^{\circ} \mathrm{C} / \mathrm{min}$ from -40 to $400^{\circ} \mathrm{C}$. Thermal gravimetric analysis of polymer gel electrolytes was performed using Simultaneous DTA-TGA Apparatus (Shimadzu DTG-60) under a nitrogen atmosphere $(20 \mathrm{~mL} / \mathrm{min})$ with $10^{\circ} \mathrm{C} / \mathrm{min}$ heating rate from 30 to $500^{\circ} \mathrm{C}$. X-ray diffraction patterns of polymer gel electrolytes were obtained using Rigaku $\mathrm{D} / \mathrm{Max}-2200 / \mathrm{PC}$ in the range of $10-90^{\circ}\left(\mathrm{Cu} K_{\alpha 1}\right.$ radiation, $\lambda=1.54056 \AA$ ).

\section{Results and discussion}

Table 1 shows the effect of the concentration of KI on the ionic conductivity of polymer gel electrolytes at room temperature $\left(25^{\circ} \mathrm{C}\right)$. Increase in the KI concentration from 0.2 to $1 \mathrm{~mol} / \mathrm{L}$ affects the ionic conductivity values in a positive direction, attaining a maximum value at $0.8 \mathrm{~mol} / \mathrm{L}$. Salt concentration effect can be attributed to the increasing amount of charge carriers/mobile ions in the gel electrolytes. Such result has been stated in the literature [7]. To determine the ionic transport mechanism, the ionic conductivity-temperature relationship of gel electrolytes based on PVA was investigated using the Arrhenius equation [8] and given in Fig. 2 for different concentrations of KI. The Arrhenius equation is shown below

$$
\ln (\sigma)=\ln (A)-E_{\mathrm{a}} \frac{1}{R T},
$$

where $E_{\mathrm{a}}$ is the activation energy, $A$ is a constant, $R$ is the molar gas constant, and $T$ is the absolute temperature. The linearity of the plot between $1 / T$ and $\ln \sigma$ for all KI concentrations is apparent as seen in Fig. 2.

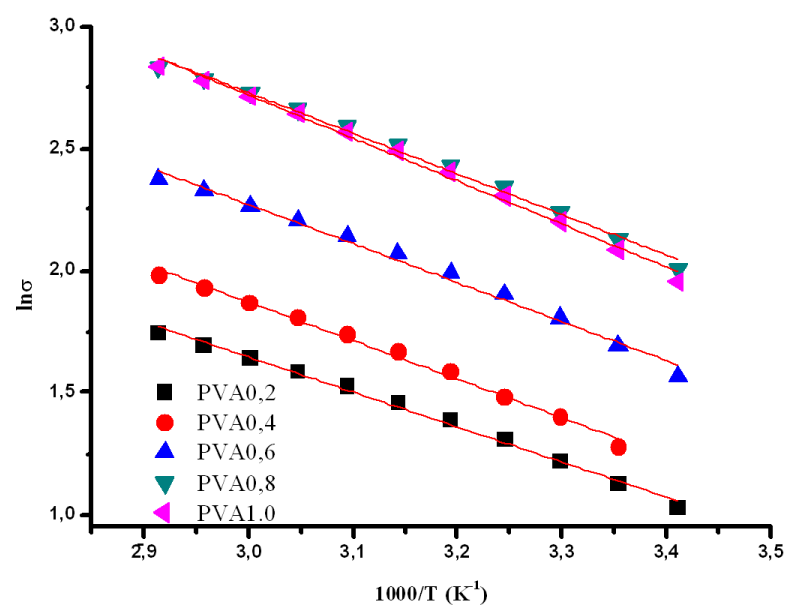

Fig. 2. $\ln \sigma-1 / T$ plot of gel electrolytes.

The activation energies for the gel electrolytes based on PVA are given in Table I. PVA0.8 shows the best efficiency in terms of conductivity.

\section{TABLE I}

Influence of KI concentration on the ionic conductivity of polymer gel electrolytes.

\begin{tabular}{c|c|c|c}
\hline \hline $\begin{array}{c}\text { Gel } \\
\text { electrolyte } \\
\text { code }\end{array}$ & $\begin{array}{c}\mathrm{KI} \\
{[\mathrm{mol} / \mathrm{L}]}\end{array}$ & $\begin{array}{c}\sigma \\
{[\mathrm{mS} / \mathrm{cm}]} \\
\mathrm{RT}\end{array}$ & $\begin{array}{c}E_{\mathrm{a}} \\
{\left[\mathrm{kJ} \mathrm{mol}^{-1}\right]}\end{array}$ \\
\hline PVA0.2 & 0.2 & 3.09 & 11.90 \\
PVA0.4 & 0.4 & 3.60 & 13.12 \\
PVA0.6 & 06 & 5.44 & 13.29 \\
PVA0.8 & 0.8 & 8.41 & 13.80 \\
PVA1.0 & 1.0 & 8.04 & 14.63
\end{tabular}

The DSC results show that in comparison to pure PVA, the endothermic responses shift towards lower temperature and peak area becomes large (Fig. 3a). While the melting point $\left(T_{\mathrm{m}}\right)$ of the pure PVA is $222^{\circ} \mathrm{C}\left(\Delta H_{\mathrm{m}}=\right.$ $\left.24 \mathrm{~J} \mathrm{~g}^{-1}\right)$, glass transition temperature $\left(T_{\mathrm{g}}\right)$ is observed at $34^{\circ} \mathrm{C} . T_{\mathrm{m}}$ is compatible with literature [9]. It was reported that the superiority of the amorphous phase is important to attain high ionic conductivity [10]. Although $T_{\mathrm{g}}$ of pure PVA has been given as around $80^{\circ} \mathrm{C}[5,11]$, our $T_{\mathrm{g}}$ is too low. It can be concluded that $T_{\mathrm{g}}$ values may depend on the molecular weights of PVA's. Compared to PVA, certain changes in the DSC thermograms of gel electrolytes such as the decrease in melting temperature and the change in glass transition region indicate the salt-polymer interaction.

Figure 3b shows the thermogravimetric curves of PVA and gel electrolytes. The starting temperature of the thermal degradation for PVA is higher than that of gel 


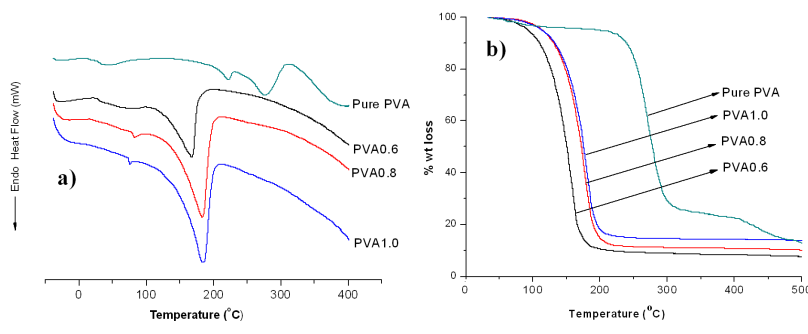

Fig. 3. DSC (a) and TGA (b) thermograms of pure PVA and gel electrolytes.

electrolytes. It was reported that the salt addition in PVA causes a decrease in decomposition temperature since $-\mathrm{OH}$ groups in PVA backbone form complex with salt cation [6]. In the present study, significantly reduced thermal resistance of gel electrolytes can be attributed to that strong interaction of salt cation with $-\mathrm{OH}$ groups of PVA.

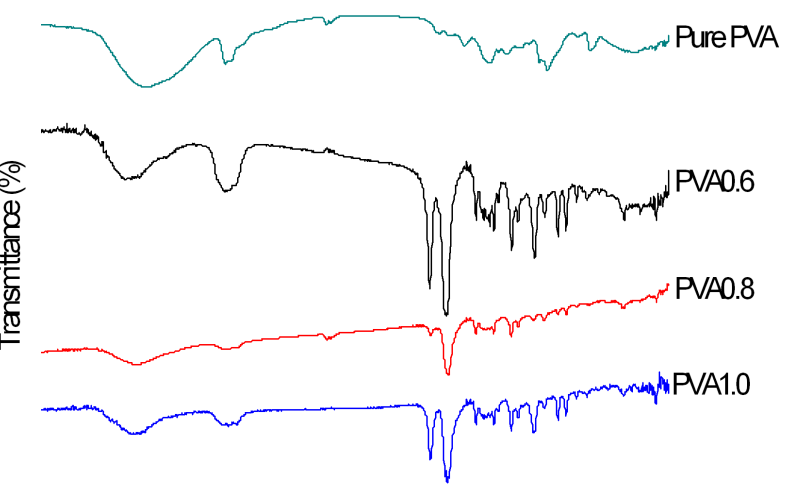

\section{$\begin{array}{llllllll}3500 & 3000 & 2500 & 2000 & 1500 & 1000 & 500 & 0\end{array}$ \\ Wávenumber $\left(\mathrm{am}^{-1}\right)$}

Fig. 4. FTIR spectra of pure PVA and gel electrolytes.

FT-IR spectra were used to determine the interaction between PVA and liquid electrolyte (Fig. 4). In the PVA spectrum, the band observed in the $3000-3600 \mathrm{~cm}^{-1}$ region is assigned to the $\mathrm{O}-\mathrm{H}$ stretching of PVA because of strong inter/intra-molecular hydrogen bond [10, 11]. While the band at $1429 \mathrm{~cm}^{-1}$ belongs to bending vibration of $\mathrm{O}-\mathrm{H}, \mathrm{C}=\mathrm{O}$ stretching peak can be seen at $1717 \mathrm{~cm}^{-1}$. The absorption band at around $1096 \mathrm{~cm}^{-1}$ is attributed to $\mathrm{C}-\mathrm{O}$ stretching present in the PVA structure [11]. The changes in the peak intensities and shifting are important to confirm the complex formation between the alkali salt and the polymer. The significant change is observed for the stretching and bending vibration of $\mathrm{O}-\mathrm{H}$ in PVA. In case of the polymer gel electrolytes, intensity of stretching and bending vibration of $\mathrm{O}-\mathrm{H}$ peaks decreases. The broadening in the hydroxyl band region is seen for all the gel electrolytes and it is more evident for PVA0.8, which is the gel electrolyte having the highest ionic conductivity at room temperature. The increased intensities of $\mathrm{C}=\mathrm{O}$ stretching (in comparison to PVA) and shifting in the spectra of gel electrolytes are clear, which verify the complex formation.

The XRD patterns for PVA gel electrolytes are given in Fig. 5. The amorphous character of the gel electrolyte is very important to improve both the easy transport of ions in the electrolyte and the ionic conductivity. PVA displays the semi-crystalline nature [6]. It is clear that the XRD peak of PVA $\left(2 \theta=19.8^{\circ}\right)$ broadens with addition of $\mathrm{KI}+\mathrm{I}_{2}$ (Fig. 5) and therefore, the improvement in amorphous nature of gel electrolytes is observed depending on the KI concentration.

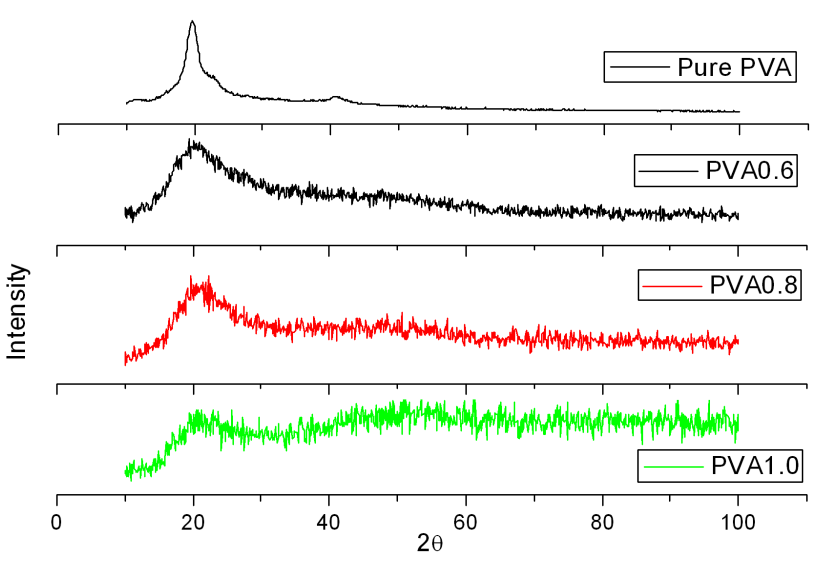

Fig. 5. XRD of pure PVA and gel electrolytes.

\section{Conclusion}

In the current study, polymer gel electrolytes based on PVA were prepared and ionic conductivity and characterizations of the gel electrolytes were investigated. The ionic conductivity of gel electrolytes were found to depend upon the salt concentration. The highest ionic conductivity at room temperature is $8.41 \mathrm{mS} / \mathrm{cm}$, which is a high value to use in applications. Ionic conductivitytemperature relationship is well described by the Arrhenius equation for all the gel electrolytes. Characterization studies show that the amorphous property of the polymer gel electrolytes depends on the concentration of KI.

\section{Acknowledgments}

This work was supported by Scientific Research Projects Coordination Unit of Istanbul University. Project number: 49553.

\section{References}

[1] S.N. Bhad, V.S. Sangawar, Chem. Sci. Trans. 1, 653 (2012).

[2] Y. Wang, Sol. En. Mater. Sol. Cells 93, 1167 (2009). 
[3] C. Song, L. Zhang, Y. Wang, X. Yan, D. Zhao, J. Mater. Sci. 48, 8153 (2013).

[4] H. Yang, M. Huang, J. Wu, Z. Lan, S. Hao, J. Lin, Mater. Chem. Phys. 110, 38 (2008).

[5] C.-W. Liew, S. Ramesh, A.K. Arof, Int. J. Hydrog. En. 39, 2953 (2014).

[6] A.L. Saroj, R.K. Singh, J. Phys. Chem. Solids 73, $162(2012)$.

[7] M.M. Noor, M.H. Buraidah, S.N.F. Yusuf, M.A. Careem, S.R. Majid, A.K. Arof, Int. J. Photoen. 2011 960487 (2011).

[8] Z. Lan, J. Wu, D. Wang, S. Hao, J. Lin, Y. Huang, Sol. En. 80, 1483 (2006).
[9] D. Mondal, Md.M.R. Mollick, B. Bhowmick, D. Maity, M.K. Bain, D. Rana, A. Mukhopadhyay, K. Dana, D. Chattopadhyay, Prog. Nat. Sci. Mater. Int. 23, 579 (2013).

[10] S. Bhavani, Y. Pavani, M. Ravi, K. Kiran Kumar, V.V.R. Narasimha Rao, Am. J. Polym. Sci. 3, 56 (2013).

[11] N.-T. Nguyen, J.-H. Liu, Eur. Polym. J. 49, 4201 (2013). 